\title{
Effect of Using Clinical Pathway on Nursing Care of Neonates with Respiratory Distress Syndrome
}

\author{
Samah Mostafa Khalaf, Lecturer of Pediatric Nursing \\ Faculty of Nursing, Benha University, Egypt \\ Basma R. Abdel Sadik: Assistant Professor of Pediatric Nursing \\ Faculty of Nursing, Benha University, Egypt
}

\begin{abstract}
Respiratory distress syndrome (RDS) considered one of the most serious disorders which leading to high morbidities and mortalities among neonates. It occurs when a neonate's lungs aren't fully developed and unable to gain enough oxygen. The aim of this study was to determine the effect of clinical pathway on nursing care of neonates with respiratory distress syndrome. A quasi-experimental design was used. This study was carried out at neonatal intensive care units affiliated to Benha University Hospital and Benha specialized hospital of children and Benha Teaching Hospital at Benha city. A convenient sample of (150) nurses and all the available neonates with respiratory distress syndrome (150 neonates). Three tools were used;ToolI- A structured interviewing schedule, which consists of four parts: Nurses' characteristics, neonates' characteristics, Nurses' knowledge regarding neonatal respiratory distress syndrome, and Nurses' Knowledge about nursing care of neonates with Respiratory distress syndrome. Tool II- Clinical pathway of care checklist. Tool III-Neonatal clinical outcome assessment sheet. Results of this study revealed that, there was statistically significant differences regarding the effect of clinical pathway on the clinical outcomes of studied neonates pre and post clinical pathway implementation. This study concluded that: Implementation of the clinical pathway improved nurses' knowledge and practice that reflecting obvious improvement in clinical outcomes of neonates with respiratory distress syndrome. The study recommended that Clinical pathway on nursing care of neonates with respiratory distress should be applied for neonates with respiratory distress at different settings.
\end{abstract}

Key words: Clinical pathway, nursing care, respiratory distress syndrome. 


\section{Introduction}

Respiratory distress syndrome (RDS), formerly known as hyaline membrane disease. It is the most common cause of respiratory distress of the preterm neonates, because lung immaturity is associated with inadequate production of pulmonary surfactant. As, it is a result of surfactant deficiency, which causes increased surface tension in the air-liquid interface of the terminal respiratory units , which leading to atelectasis, increased ventilation perfusion mismatch, and potential lung injury due to a marked pulmonary inflammatory response ${ }^{(1)}$.

Respiratory distress syndrome in neonates results from a combination of structural and functional immaturity of the lungs, as a result of the final unfolding of the alveolar septa, which increases the surface area of the lungs. Whereas, it occurs during the last trimester of pregnancy, Moreover, neonates are born with numerous underdeveloped and many uninflatable alveoli (2). Clinically, RDS presents with early respiratory distress comprising; cyanosis, tachypnoea, intercostals, subcostal, and sternal recession, expiratory grunting, and diminished breath sounds. So that, any delay in diagnosis of airway abnormalities may be a life threatening ${ }^{(3)}$. Respiratory distress syndrome primarily, considered a disease of preterm neonates, it also, can occur in those born close to or at term. It should be considered as a differential diagnosis in any neonate with early respiratory distress. In rare cases, neonates with RDS may suffer from genetic conditions such as; surfactant protein-B or ABCA3 deficiency. So, surfactant therapy considered one of the main parts of management ${ }^{(4) \text {. }}$

There are many factors can increase the risk of RDS include; one sibling had RDS, mothers suffering from diabetes, cesarean delivery or induction of labor problems with delivery that reduce blood flow to the neonate and multiple pregnancies ${ }^{(5)}$.

Management of RDS includes all the general measures required for any preterm infant, as well as those instituted to correct imbalances. There are many supportive measures most crucial to a favorable outcome which include; maintaining adequate ventilation and oxygenation with continuous positive airway pressure (CPAP), or mechanical ventilation, in addition to, maintaining acid-base balance, neutral thermal environment, adequate tissue perfusion and oxygenation, adequate hydration and electrolyte status and finally prevention of neonatal hypotension ${ }^{(6)}$.

Despite recent advances in the perinatal management of neonatal respiratory distress syndrome (RDS), conflict still exists as respiratory distress syndrome 
(RDS) is a major contributor to neonatal mortality worldwide. As the prevalence rate of neonatal respiratory distress syndrome in Egypt was 11,193.Whereas, the most cases of RDS occur in neonates born before 37 weeks. Additionally, the incidence of RDS increases with decreasing gestational age, especially infants born below 30 weeks gestation are at the greatest risk for $\operatorname{RDS}^{(7) \text {. }}$

Clinical pathway care is a structured, multidisplinary plan of care designed to support the implementation of clinical guidelines and protocols of care. It is designed to support clinical management, clinical and non-clinical resource management, clinical audit and also financial management. It provide detailed guidance for each stage in the management of a patient whether adult or pediatric patient with a specific condition over a given time period and include progress and outcomes details. Moreover, it aims to improve particularly the continuity and coordination of care across different disciplines and sectors ${ }^{(8)}$.

Nurses working at neonatal intensive care units have a great role in management of neonates with RDS involves all the observations and interventions described for high-risk neonates. In addition, the nurse is concerned with the complex problems related to respiratory therapy.
Nursing care of neonates with RDS is demanding. Though, paying meticulous attention to subtle changes in the neonate's oxygenation status, particularly in regard to medication administration ${ }^{(9)}$.

\section{Significance of the Study:}

The preterm birth is estimated by $10 \%$ $12 \%$ from neonates born in Egypt $^{(9)}$. Whereas, respiratory distress syndrome (RDS) is a problem often seen in premature neonates. This condition often gets worse for 2 to 4 days after birth and improves slowly after that. Some infants with severe respiratory distress syndrome may die. This most often occurs between the second day and the fourth day of birth. It can be fatal, it may also lead to longterm complications due to either receiving too much oxygen or because organs lacked oxygen. Therefore, this study hoping to reduce mortality and morbidity rates of neonates with RDS through enhancing nurses' knowledge and practice by using the clinical pathway nursing intervention (22).

\section{Aim of the study:}

The aim of this study was to: Determine the effect of clinical pathway on nursing care of neonates with respiratory distress syndrome

\section{Research Hypotheses:}

- Nursing care of neonates with respiratory distress syndrome 
significantly will be improved after implementing the clinical pathway intervention.

- Neonates with respiratory distress syndrome who will exposed to the clinical pathway will have less demand of oxygen, decreased frequency of daily suctioning, and decreased length of hospital stay.

\section{Subjects and method:}

\section{Research Design:}

A quasi- experimental research design was utilized.

\section{Settings:}

The study was carried out at neonatal intensive care units at Benha city as the following:

- Benha Specialized Hospital for Children affiliated to Ministry of Health . It included two units. These units are for neonates having different diagnosis. One of them contained (14) incubators and the other unit contained (26) incubators.

- Benha University Hospital. As it include two NICUs contains (16) incubators in each unit 8 incubators.

- Benha Teaching Hospital. It includes one NICU composed of incubators

\section{Subjects:}

\section{It consisted of two groups:}

Group1: The first group consists of a convenient sample consists of (150) male and female nurses who are working at the above mentioned settings were taken regardless their gender and years of experience at neonatal intensive care unit more than 6 months

Group 2: consists of a purposive sample of neonates with RDS (150- neonates) were included after fulfilling

\section{-Inclusion criteria:}

- Both sexes Gestational age $28 \leq 36$ weeks.

- $\quad$ The current weight from $1500 \leq 2500$ grams.

- Respiratory distress which manifested by the criteria

a-Tachypnea more than $60 \mathrm{c} / \mathrm{m}$

b-Having mild to moderate chest retraction.

\section{Exclusion criteria:}

Neonates with major malformation, congenital heart disease or on mechanical ventilation

\section{Tools of Data Collection:}

There were three tools utilized to collect the required data. Those tools as the following: 
Tool I: A structured interviewing schedule: It was developed by the researchers after reviewing the related literatures (Negi, et al., 2012, Martin and

Fanaroff, 2013, and David et al.,2013), and it was written in Arabic language to suit study sample. It composed of four parts

Part (1): Assess nurses' characteristics, such as; age, gender qualifications, years of experience, attendance of training courses.

Part (2): Assess characteristics of the studied neonates such as; gestational age, gender, current age, weight on admission and current weight.

Part (3): Nurses' knowledge related neonatal respiratory distress syndrome, which includes their knowledge about; definition, causes, clinical manifestations, diagnosis and management of neonates with RDS. The total questions were 7 and in a form of multiple choice questions.

Part (4): Nurses` knowledge regarding nursing care of neonates with RDS, such as; knowledge about maintenance of body temperature, proper fluid management, good nutritional support, circulation, oxygen therapy and suctioning of the neonate with RDS, care of neonate on ventilator, blood gases estimation, prevention of nosocomial infection, medication administration and prognosis
Nurses' knowledge will be scored as

\section{following:}

- Correct and complete answer was scored (2)

- Correct and incomplete answer was scored (1)

- Wrong answer or don't know and was scored (0)

\section{The total score of nurses' knowledge}

were calculated and classified into three levels as following:

- $60 \% \downarrow$ will be considered poor knowledge.

- $60-\downarrow 75 \%$ will be considered fair knowledge.

- 75-100 \% will be considered good knowledge.

\section{Tool II: Clinical pathway for care of} neonates with RDS checklist:

It was adopted from (European Consensus Guidelines on the Management of Neonatal Respiratory Distress Syndrome in Preterm Infants, 2013). It was applied to assess daily nursing care provided to neonates with RDS inside the incubator. The total practices were 10 practices. It included the following practices: which include 64) items as the following:

1- Assess respiratory status by counting for full one minute with a timer and when the baby is quiet and preferably when baby is not hungry or immediately after feeds (3items) 
2-Maintain thermo neutral environment by caring the infant under radiant warmer or in incubator (2 items)

3- Ensuring normal blood glucose levels (6 items)

4-Monitoring the vital parameters (9items).

5-Provide supplemental oxygen and ventilation (10 items)

6-Provide good nutritional support with intravenous fluids and electrolytes (5items)

7- Suctioning of the neonate either through oral or nasal suctioning (10items)

8- Check regularly blood gases (5items)

9-Prevent nosocomial infection and apply a septic technique (7items)

10- Communicate effectively with parents through out length of hospital stay of the neonate and at discharge care and follow-up care (7items)

\section{-Scoring System for practice of the}

studied nurses.

Scoring system for nurses performances will be as follows:

- Done correctly and complete will score (1)

- Done incorrect or not done well will score $(0)$

The total score of nurses' practice will calculated and classified as follow:

- 60 to less than 75 will be considered unsatisfactory.

- $\quad 75-100 \%$ will be considered satisfactory
Tool III- Neonates' medical outcomes assessment sheet: It was developed by the researchers to assess the improvement of neonates' condition after application of the clinical pathway. It included; feeding improvement, $\mathrm{O}_{2}$ requirement, and length of hospital stay.

\section{Preparatory phase:}

\section{Validity and Reliability}

The researchers reviewed the past, current regional and international related literatures covering all aspects of the study using textbooks, articles, journal and scientific magazines. This helped the researchers to be acquainted with the research problem and guided them in developing the study tools. To measure content validity of the study tools, the researchers assure that items of the tools were adequately represent what are supposed to measure by presented it to five experts including; three in Pediatric nursing from the Faculty of Nursing Cairo, El-Menofia, Benha University, and two in neonatal medicine from the Faculty of medicine Benha University, to test the content validity. Modifications of the tools were done according to the experts' judgment on clarity of sentences, appropriateness of contents and sequence of items. The experts' agreed on the content, but recommended minor language changes that would make the information 
clearer and more precise. The suggested changes were made. Internal consistency reliability of all items of the tools was assessed using Chronbach's Alpha test. It was 0.83 for the structured interviewing schedule, and 0.86 for nurses' observation checklist.

\section{Method:}

\section{Exploratory phase:}

\section{Ethical considerations and human rights:}

An official permission to conduct the study was obtained from the hospital mangers. Then participation in the study was voluntary; each nurse was informed about the purpose, procedure, benefits, and nature of the study and each nurse had the right to withdraw from the study at any time without any rationale, then oral/written consent obtained from them. Subjects were informed that obtained data will not be included in any further researches. Confidentiality and anonymity of each subject was assured through coding of all data and all information has taken was protected.

\section{Pilot Study:}

It was conducted on $10 \%$ of the total study sample (15 nurses) to evaluate the feasibility, reliability, and clarity of the tools .It was conducted to test the applicability of the tools, find out the possible obstacles and problems that might face the researchers and interfere with data collection. Additionally, detect any problems peculiar to the statements as sequence of questions and clarity. It was also helped to estimate the time needed for data collection, as it was 20 minutes.

\section{Field of Work:}

Data were collected from the beginning of January 2016 to the beginning of August 2016. Immediately after the ethical approval was obtained; the researchers obtained oral consents from nurses who included in the study after an explanation of the aim, tools, benefits and the duration of the study to gain their cooperation. The researchers then started to interview each nurse individually and this took about 1520 minutes for assessing knowledge. The researchers then started to assess care provided by nurses during their actual work for each neonate (routine care) 3days / week with follow up of neonates progress condition before and after the clinical pathway. The researchers were available by rotation 3 days per week: Sunday in Benha University Hospital, and Monday in the Specialized Pediatric Hospital and Tuesday in Teaching Hospital in Benha City. At the beginning of the first session, an orientation of the contents was listed and then explanation, demonstration and re demonstration were done. After finishing data collection the actual nursing care was 
assessed and the clinical pathway intervention applied to nurses about care of neonates after one or two days of admission of neonates.

\section{Procedure:}

\section{- Preparation phase:}

It was concerned with designing and testing different data collection tools, in addition, the administrative arrangements to carry out the study as well as to conduct the pilot study. In the beginning, the researchers introduce themselves to the nurses. Nurses who accept to participate in the study individually interviewed by the researchers to explain the nature, purposes, and the desired outcomes of the study and an oral consent was obtained from these nurses.

\section{- Implementing phase:}

Data were collected from the beginning of January 2016 to the beginning of August 2016. The researchers were available by rotation 3 days per week: Sunday in Benha University Hospital, and Monday in the Specialized Pediatric Hospital and Tuesday in Teaching Hospital in Benha City during their working shifts (Saturday, Monday, and Tuesday) in the morning and afternoon shifts by rotation in the previously mentioned study settings. Each nurse was interviewed individually for $15-20$ minutes to fill out the structured interviewing questionnaire schedule (Tool
1). The researchers clarified and answered any related questions. Then, each nurse was observed during their practice on morning and afternoon shifts using nurses observational check list by the same researcher (Tool 2). The time needed for each observation for each nurse was 20-25 minutes for three times during providing of care for neonates with RDS.

\section{Clinical Pathway Application,}

\section{Implementation, and Evaluation:}

Clinical Pathway intervention was designed based on the actual needs assessment of nurses then implemented and evaluated. The aim of this intervention was to upgrade nurses' knowledge and improve their practice regarding care of neonates with RDS. The application of the clinical pathway intervention was carried out in the previously mentioned study settings with the studied nurses whereas, the theoretical contents were provided through three teaching sessions; each session took 20-25 minutes.

As, the contents related to RDS (definition, causes, clinical manifestations, diagnosis and management). The studied nurses were divided into (30) groups, each group consisted of 4-5 nurses. The researchers gave each nurse a clinical pathway guidelines related to care of neonates with RDS in addition to the teaching sessions to 


\section{Tanta Scientific Nursing Journal}

assure understanding and clear any

RDS checklist, in the form of short sessions misunderstanding.

Training of nurses was conducted using a laptop with MS Power Point presentations 2010 made from contents of the clinical pathway guidelines. according to working circumstances, there mental and physical readiness.

The clinical pathway intervention was implemented over three weeks period in addition to one week for pre and post-test. A time schedule suitable for nurses was developed to conduct the clinical pathway that included; date, place, topic, time and duration of each session.

At the beginning of the first session an orientation to the clinical pathway intervention and its importance and outcomes were explained. In addition, a feedback about the previous session was done and the objectives of the new topic were explained. Simple words and Arabic language were used to suite the nurses' level of understanding. At the end of each session, nurses' questions were discussed to correct any misunderstanding.

In addition to re-demonstration for practical procedures.As regards the practical sessions, the nurses' practices were assessed through pre test during their actual care. The pre determined procedures before provision of any information (pretest) utilizing the clinical pathway of care of neonates with from 30-35 minutes for each practical session. The total practical sessions composed of 6 sessions divided on the nurses' groups and related to nurses' actual care of neonates with RDS. The contents of these sessions include; proper fluid management, oxygen therapy care and ventilation, suctioning of the neonate with RDS, care of neonate on ventilator and blood gases estimation

Different teaching strategies were used for implementation of the clinical pathway intervention such as lectures, small group discussion, brain storming, role play, demonstration and re-demonstration using real objects. Suitable teaching aids as booklet, colored posters, doll and real objects were prepared especially for practice. Nurses were motivated to cooperate and participate actively in different stages of the study.

\section{Administrative design}

An official permission for data collection was obtained from the hospitals' managers through submission of official letters issued from the dean of Benha faculty of nursing. The title, objectives, and outcomes of the study were illustrated as well as the main data items to be covered, and the study was carried out after gaining the necessary permission. The study was carried out 
during the period from beginning of January 2016 to the beginning of August 2016.

\section{Statistical design}

The collected data revised, organized, tabulated and analyzed by using SPSS (Statistical Package for the social Science Software) statistical package version 20 on IBM compatible computer. Numerical data (Quantitative data) was presented in tables by using Mean, Standard deviation (X \pm $\mathrm{SD})$ and analyzed by applying t-test for normally distributed variables, while qualitative data were expressed as frequency and percentage and chi-square was used. Additionally, other statistical tests such as Independent $t$ test was used as a parametric test of significance for comparison between two samples means. Pearson correlation (r) was used to measure the correlation between quantitative variables.

P-value at .05 was used to determine significance regarding:

- P-value > .05 to be statistically insignificant.

- P-value $\leq 05$ to be statistically significant.

- P-value $\leq 001$ to be high statistically significant.

\section{Evaluation Phase:}

Upon the completion of the clinical pathway implementation, the post test evaluation was conducted to evaluate the outcomes by using the same pre test tools

\section{Results:}

Table (1) :Shows that, half of the studied nurses $(50 \%)$ had age between $20<25$ years with mean age of $25.46 \pm 5.262$ years, with mean years of experience was $5.65 \pm 4.671$ years. While, more than two thirds $(70 \%)$ of them had diploma of secondary school of nursing. Also, half of them (50\%) had attended training programs related to NICU.

Table (2): Represents that, more than two thirds $(70 \%)$ of the studied neonates were males. While, the rest of them were females. Also, more than two thirds $(69.30 \%)$ of them had current age in days of $1<5$ days.

Table(3) :Illustrates, distribution of the studied nurses according to their knowledge about RDS before and after clinical pathway implementation. As, there was an improvement in their knowledge in most items on post clinical pathway implementation phase compared with pre clinical pathway implementation phase knowledge with high statistical significant difference $(\mathrm{p}<0.001)$.

Table(4) :Views, distribution of the studied nurses according to their knowledge about nursing care of neonates with RDS before and after clinical pathway implementation whereas, there was a highly statistical significant difference $(\mathrm{p}$ $<0.001)$ in the studied nurses' post clinical 
pathway implementation knowledge scores compared with pre clinical pathway implementation knowledge scores regarding their nursing care of neonate with RDS.

Figure (1) :Reveals, percentage distribution of total knowledge scores of the studied nurses about RDS before and after clinical pathway implementation.As,more than two thirds $(69 \%)$ of them had poor knowledge pre clinical pathway compared with more than three quarters $(78 \%)$ of them had good knowledge post clinical pathway

Table (5) :Shows distribution of the studied nurses regarding their competent practice scores before and after the clinical pathway implementation. As, there was a statistical significant difference $(p<0.05)$ in the studied nurses' post clinical pathway implementation practice scores compared with pre clinical pathway implementation.

Figure (2): Shows percentage distribution of total practice scores of the studied nurses before and after clinical pathway implementation. As, the majority of them $(91.2 \%)$ had incompetent practice pre clinical pathway compared with $78 \%$ of them had competent practice post clinical pathway implementation

Table (6) :Clarifies, percentage distribution of the studied neonates regarding the effect of clinical pathway on their condition. Whereas, increased o2 requirements of the majority the studied neonates $(89.3 \%)$ before implementation of clinical pathway compared with post clinical pathway. On the other hand, more than half (54\%) of them had length of hospital stay less than 10 days after implementation of clinical pathway compared with the pre implementation of pathway.

Table (7):Shows, percentage distribution of the studied nurses' total knowledge and practice scores before and after clinical pathway implementation As, the more than two thirds of them had poor knowledge $(69.3 \%)$ before clinical pathway implementation while more than three quarters $(78.00 \%)$ of them had good knowledge post clinical pathway implementation. Regarding their practices' total scores, the majority (78.2\%)of them had competent practice post clinical pathway implementation compared with 91.4\% of them had incompetent practice pre clinical pathway implementation.

Table (8): Shows highly statistical significance relations between the studied nurses' knowledge and practice and their age, educational level and years of experiences. On the other hand, there was no statistical significance between gender and their knowledge and practice.

Table (9):Shows correlation between studied nurses' knowledge and practices pre and post clinical pathway implementation, it was revealed that there were a highly statistical significance correlation between them pre and post program implementation. 
Table (1): Percentage Distribution of the studied nurses according to their characteristics $($ no $=150)$

\begin{tabular}{|c|c|c|}
\hline Nurses' characteristics & No(150) & $\%$ \\
\hline \begin{tabular}{|c|} 
Age in years \\
$-\quad<20$ \\
$-\quad 20<25$ \\
$-\quad 25<30$ \\
$-\quad \geq 30$
\end{tabular} & $\begin{array}{c}5 \\
75 \\
45 \\
25\end{array}$ & $\begin{array}{l}3.3 \\
50.0 \\
30.0 \\
16.7\end{array}$ \\
\hline \multicolumn{3}{|c|}{$25.46 \pm 5.262$} \\
\hline $\begin{array}{l}\text { Gender } \\
\text { male } \\
\text { Female }\end{array}$ & $\begin{array}{c}13 \\
137\end{array}$ & $\begin{array}{r}8.7 \\
91.3\end{array}$ \\
\hline \begin{tabular}{|c|} 
Years of Experience \\
$\quad<3$ \\
$3<6$ \\
$6<9$ \\
$\geq 9$
\end{tabular} & $\begin{array}{l}58 \\
35 \\
28 \\
29\end{array}$ & $\begin{array}{l}38.7 \\
23.3 \\
18.7 \\
19.3\end{array}$ \\
\hline $\mathrm{X} \pm \mathrm{SD}$ & & \\
\hline $\begin{array}{l}\text { Academic Qualification } \\
\text { - Diploma of Secondary Nursing School } \\
\text { - Diploma of Technical Institute of Nursing } \\
\text { - Bachelor degree of Nursing Science }\end{array}$ & $\begin{array}{c}105 \\
40 \\
5\end{array}$ & $\begin{array}{r}70.0 \\
26.7 \\
3.3\end{array}$ \\
\hline $\begin{array}{l}\text { Place of work: } \\
\text {-Benha University hospital } \\
\text {-Benha Teaching Hospital } \\
\text {-Benha Children Specialized Hospital }\end{array}$ & $\begin{array}{c}22 \\
24 \\
104\end{array}$ & $\begin{array}{l}14.7 \\
16.0 \\
69.3\end{array}$ \\
\hline $\begin{array}{l}\text { Training programs related to NICU } \\
- \text { Yes } \\
- \text { no }\end{array}$ & $\begin{array}{l}75 \\
75\end{array}$ & $\begin{array}{l}50.0 \\
50.0\end{array}$ \\
\hline
\end{tabular}


Table (2): Percentage Distribution of the studied neonates according to their characteristics $($ no $=150)$

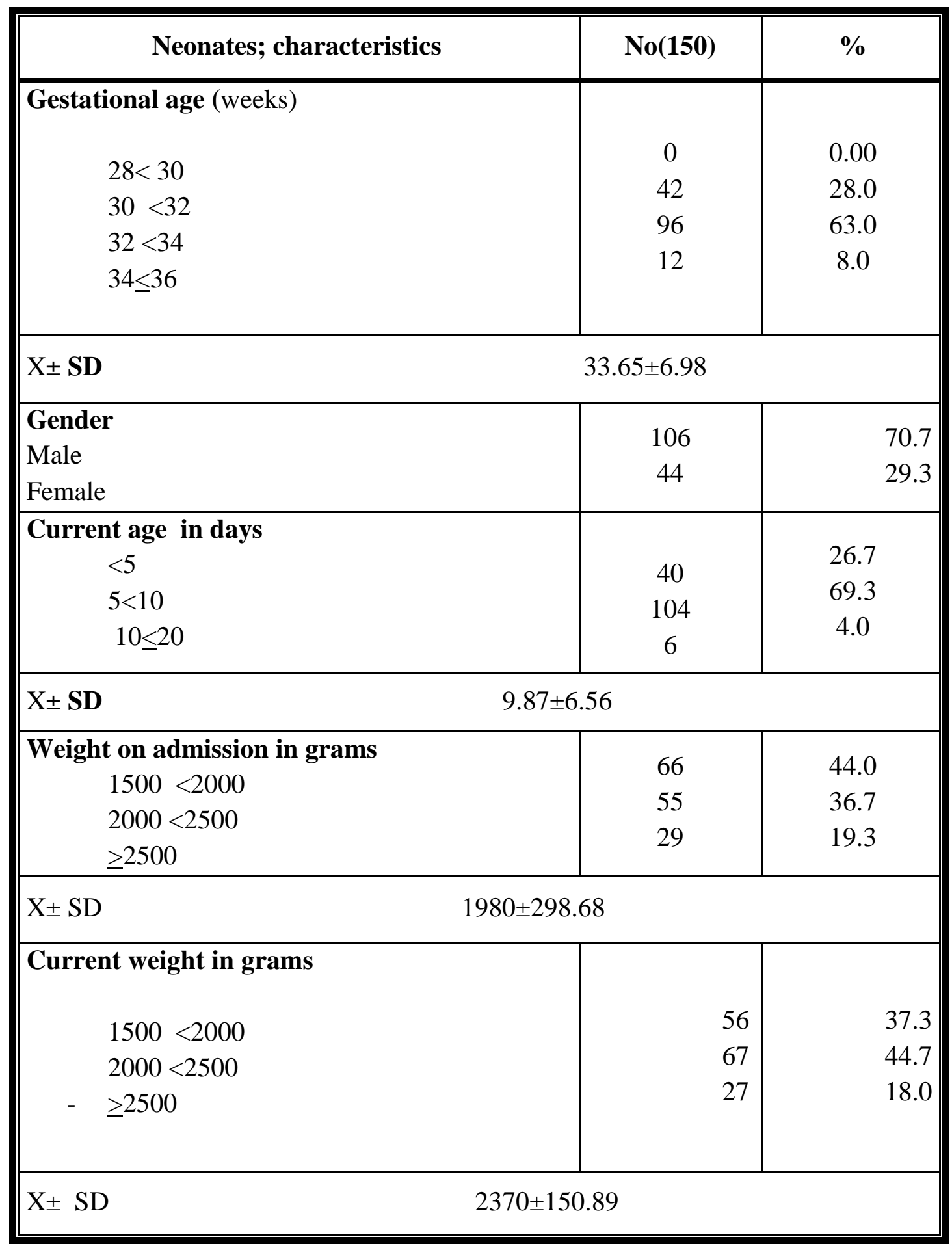


Table (3): Percentage Distribution of the studied nurses according to their knowledge about RDS before and after clinical pathway implementation $($ no=150).

\begin{tabular}{|c|c|c|c|c|c|c|c|c|c|c|c|c|c|c|}
\hline \multirow{3}{*}{$\begin{array}{c}\text { Nurses' } \\
\text { knowledge }\end{array}$} & \multicolumn{6}{|c|}{$\begin{array}{l}\text { Pre clinical pathway } \\
\end{array}$} & \multicolumn{6}{|c|}{ Post clinical pathway } & \multirow{3}{*}{$\mathbf{x}^{2}$} & \multirow{3}{*}{$P$ value } \\
\hline & \multicolumn{2}{|c|}{ Correct answers } & \multicolumn{2}{|c|}{ Incorrect answers } & \multicolumn{2}{|c|}{ Don't know } & \multicolumn{2}{|c|}{$\begin{array}{l}\text { Correct answers } \\
\end{array}$} & \multicolumn{2}{|c|}{ Incorrect answers } & \multicolumn{2}{|c|}{ Don't know } & & \\
\hline & No & $\%$ & No & $\%$ & No & $\%$ & No & $\%$ & No & $\%$ & No & $\%$ & & \\
\hline Definition of RDS & $\begin{array}{l}1 \\
7\end{array}$ & 11.3 & 119 & 79.3 & 14 & 9.3 & 142 & 94.7 & 5 & 3.3 & 3 & 2.0 & 21.19 & $\begin{array}{l}<0.0 \\
01 * *\end{array}$ \\
\hline $\begin{array}{l}\text { Signs and } \\
\text { symptoms of } \\
\text { RDS }\end{array}$ & $\begin{array}{l}1 \\
9\end{array}$ & 12.7 & 118 & 78.7 & 13 & 8.7 & 37 & 24.7 & 108 & 72.0 & 5 & 3.3 & 9.76 & $\begin{array}{l}<0.0 \\
5^{*}\end{array}$ \\
\hline $\begin{array}{l}\text { Leading causes } \\
\text { of RDS }\end{array}$ & 2 & 18.0 & 111 & 74.0 & 12 & 8.0 & 80 & 53.3 & 68 & 45.3 & 2 & 1.3 & 43.72 & $\begin{array}{ll}<0.001^{*} \\
*\end{array}$ \\
\hline Diagnosis of RDS & 5 & 38.7 & 83 & 55.3 & 9 & 6.0 & 31 & 20.7 & 118 & 78.7 & 1 & 0.7 & 20.68 & $\begin{array}{ll}<0.001 * \\
*\end{array}$ \\
\hline $\begin{array}{l}\text { Treatment of } \\
\text { RDS }\end{array}$ & 1 & 9.3 & 108 & 72.0 & 28 & 18.7 & 51 & 34.0 & 99 & 66.0 & 0 & 0.0 & 49.45 & $\begin{array}{ll}<0.001 * \\
*\end{array}$ \\
\hline Prevention & 7 & 52.0 & 72 & 48.0 & 0 & 0.0 & 42 & 28.0 & 105 & 70.0 & 3 & 2.0 & 19.95 & $<0.001^{*}$ \\
\hline
\end{tabular}

Table (4): Percentage Distribution of the studied nurses according to their Knowledge about nursing care of neonates with RDS before and after clinical pathway implementation $($ no $=150)$

\begin{tabular}{|c|c|c|c|c|c|c|c|c|c|c|c|c|c|c|}
\hline \multirow{2}{*}{$\begin{array}{c}\text { Nurses' } \\
\text { knowledge }\end{array}$} & \multicolumn{6}{|c|}{ Pre clinical pathway } & \multicolumn{6}{|c|}{ Post clinical pathway } & \multirow[b]{2}{*}{$\mathrm{x}^{2}$} & \multirow{2}{*}{ value } \\
\hline & \multicolumn{2}{|c|}{ Correct answers } & \multicolumn{2}{|c|}{ Incorrect answers } & \multicolumn{2}{|c|}{ Don't know } & \multicolumn{2}{|c|}{ Correct answers } & \multicolumn{2}{|c|}{ Incorrect answers } & \multicolumn{2}{|c|}{ Don't know } & & \\
\hline $\begin{array}{l}\text { Maintainace of } \\
\text { body temperature }\end{array}$ & 31 & 20.7 & 58 & 38.7 & 61 & 40.7 & 136 & 90.6 & 8 & 5.3 & 6 & 4.0 & 80.8 & $\begin{array}{l}<0.001^{*} \\
*\end{array}$ \\
\hline $\begin{array}{l}\text { Proper fluid } \\
\text { management }\end{array}$ & 27 & 18.0 & 42 & 28.0 & 81 & 54.0 & 103 & 68.6 & 22 & 14.6 & 25 & 16.7 & 25.8 & $\begin{array}{l}<0.001 * \\
*\end{array}$ \\
\hline $\begin{array}{l}\text { Good nutritional } \\
\text { support }\end{array}$ & 35 & 23.3 & 10 & 6.6 & 105 & 70.0 & 115 & 76.6 & 20 & 13.3 & 15 & 10.0 & 98.84 & $\begin{array}{l}<0.001 * \\
*\end{array}$ \\
\hline $\begin{array}{l}\text { Support of } \\
\text { circulation }\end{array}$ & 33 & 22.0 & 51 & 34.0 & 66 & 44.0 & 112 & 74.6 & 21 & 14.0 & 17 & 11.3 & $\begin{array}{r}177.0 \\
\quad 2 \\
\end{array}$ & $\begin{array}{l}<0.001 * \\
*\end{array}$ \\
\hline $\begin{array}{l}\text { Oxygen therapy } \\
\text { care }\end{array}$ & 28 & 18.7 & 11 & 7.3 & 111 & 74.0 & 118 & 78.6 & 11 & 7.3 & 21 & 14.0 & 91.59 & $\begin{array}{l}<0.001^{*} \\
*\end{array}$ \\
\hline $\begin{array}{l}\text { Suctioning of the } \\
\text { neonate with RDS }\end{array}$ & 17 & 11.3 & 50 & 33.3 & 83 & 55.3 & 109 & 72.6 & 20 & 13.3 & 21 & 14.0 & 21.27 & $\begin{array}{l}<0.001 * \\
*\end{array}$ \\
\hline $\begin{array}{l}\text { Care of neonate on } \\
\text { ventilator }\end{array}$ & 39 & 26.0 & 20 & 13.3 & 91 & 60.7 & 101 & 67.3 & 20 & 13.3 & 29 & 19.3 & 190.8 & $\begin{array}{l}<0.001 * \\
*\end{array}$ \\
\hline $\begin{array}{l}\text { Blood gases } \\
\text { estimation }\end{array}$ & 36 & 24.0 & 4 & 2.6 & 110 & 73.3 & 116 & 77.3 & 4 & 2.6 & 30 & 20. & 108.6 & $\begin{array}{l}<.001 * \\
*\end{array}$ \\
\hline $\begin{array}{l}\text { Prevention of } \\
\text { nosocomial } \\
\text { infection }\end{array}$ & 33 & 22.0 & 12 & 8.0 & 105 & 70.0 & 101 & 67.3 & 12 & 8.0 & 37 & & $\begin{array}{r}215.9 \\
8\end{array}$ & $\begin{array}{l}<0.001^{*} \\
{ }^{2}\end{array}$ \\
\hline $\begin{array}{l}\text { Medication } \\
\text { administration }\end{array}$ & 44 & 29.3 & 100 & 66.7 & 96 & 64.0 & 110 & 73.3 & 30 & & 10 & & 122.0 & $\begin{array}{l}<0.001^{*} \\
*\end{array}$ \\
\hline Prognosis & 13 & 8.7 & 55 & 36.7 & 82 & 54.7 & 125 & & 13 & & 12 & & 60.47 & $\begin{array}{l}{ }_{*}<.001^{*} \\
\text {. }\end{array}$ \\
\hline
\end{tabular}




\section{Tanta Scientific Nursing Journal}

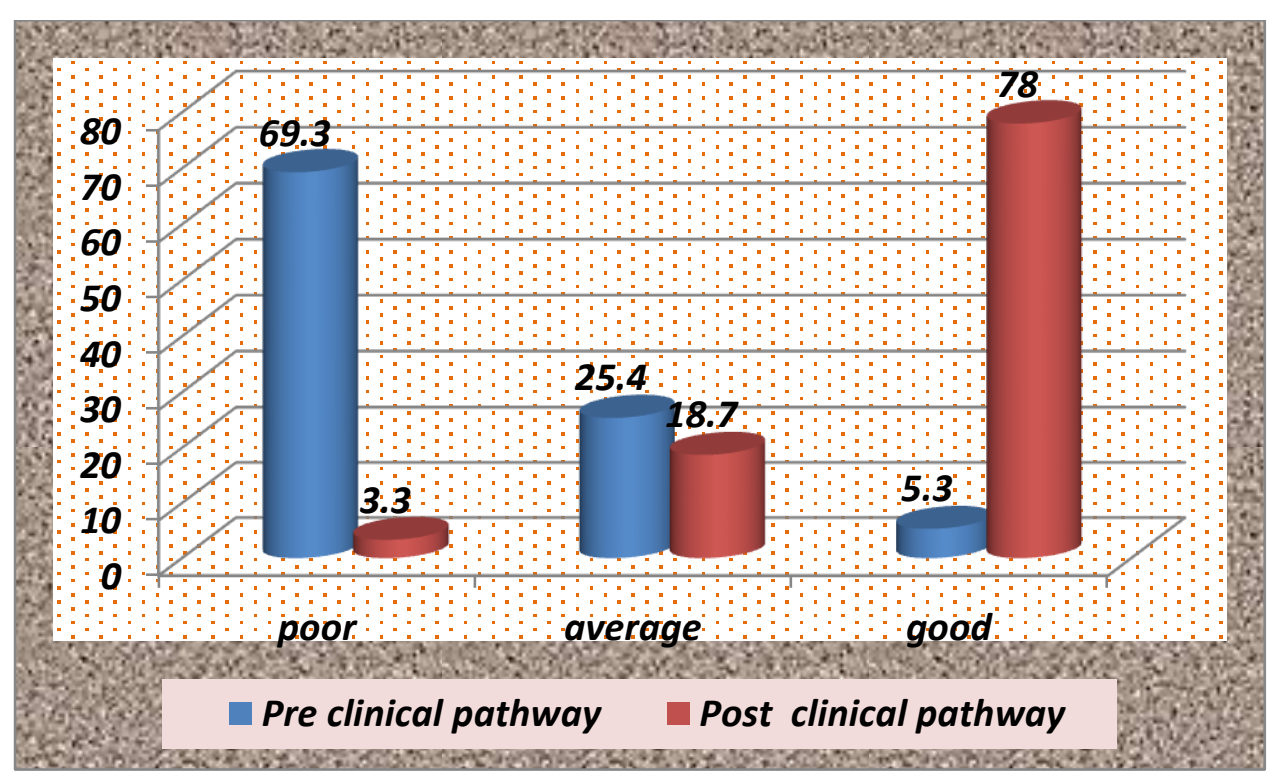

Figure (1): Percentage distribution of total knowledge scores of the studied nurses about RDS before and after clinical pathway implementation

Table (5): Distribution of the studied nurses regarding their competent practice scores before and after the clinical pathway implementation (No=150)

\begin{tabular}{|c|c|c|c|c|c|c|}
\hline \multicolumn{7}{|c|}{$\begin{array}{c}\text { Number of Studied Nurses }=(150) \\
\text { Competent practice }\end{array}$} \\
\hline \multirow[t]{2}{*}{ Items } & \multicolumn{2}{|c|}{$\begin{array}{l}\text { Before clinical } \\
\text { pathway } \\
\text { Done correctly } \\
\text { and complete } \\
\text { (total=150) }\end{array}$} & \multicolumn{2}{|c|}{$\begin{array}{l}\text { After clinical } \\
\text { pathway } \\
\text { Done correctly } \\
\text { and complete } \\
\text { (total=150) }\end{array}$} & \multirow[b]{2}{*}{$\mathbf{X}^{2}$} & \multirow[b]{2}{*}{ P valu } \\
\hline & No & $\%$ & No & $\%$ & & \\
\hline Assess respiratory status & 96 & 64.00 & 136 & 90.70 & 30.42 & $<0.05 *$ \\
\hline $\begin{array}{l}\text { Maintain thermo neutral } \\
\text { environment }\end{array}$ & 4 & 2.70 & 142 & 94.70 & 254.10 & $<0.05^{*}$ \\
\hline $\begin{array}{l}\text { Ensuring normal blood glucose } \\
\text { levels }\end{array}$ & 20 & 13.30 & 142 & 94.70 & 199.73 & $<0.05^{*}$ \\
\hline Monitoring the vital parameters & 100 & 66.70 & 78 & 52.00 & 6.68 & $<0.05^{*}$ \\
\hline $\begin{array}{l}\text { Provide supplemental oxygen and } \\
\text { ventilation }\end{array}$ & 12 & 8.00 & 94 & 62.70 & 98.09 & $<0.05^{*}$ \\
\hline $\begin{array}{l}\text { Provide good nutritional support } \\
\text { with intravenous fluids and } \\
\text { electrolytes }\end{array}$ & 24 & 16.00 & 142 & 94.70 & 187.79 & $<0.05^{*}$ \\
\hline $\begin{array}{l}\text { Suctioning of the neonate either } \\
\text { through oral or nasal suctioning }\end{array}$ & 64 & 42.70 & 82 & 54.70 & 4.32 & $<0.05^{*}$ \\
\hline Check regularly blood gases & 54 & 36.00 & 110 & 73.30 & 42.18 & $<\mathbf{0 . 0 5 *}$ \\
\hline $\begin{array}{l}\text { Prevent nosocomial infection and } \\
\text { apply a septic technique }\end{array}$ & 16 & 10.70 & 111 & 74.00 & 123.23 & $<0.05^{*}$ \\
\hline $\begin{array}{l}\text { Communicate effectively with } \\
\text { parents through out length of } \\
\text { hospital stay and at discharge }\end{array}$ & 50 & 33.30 & 86 & $\mathbf{5 7 . 3 0}$ & 17.43 & $<0.05 *$ \\
\hline
\end{tabular}




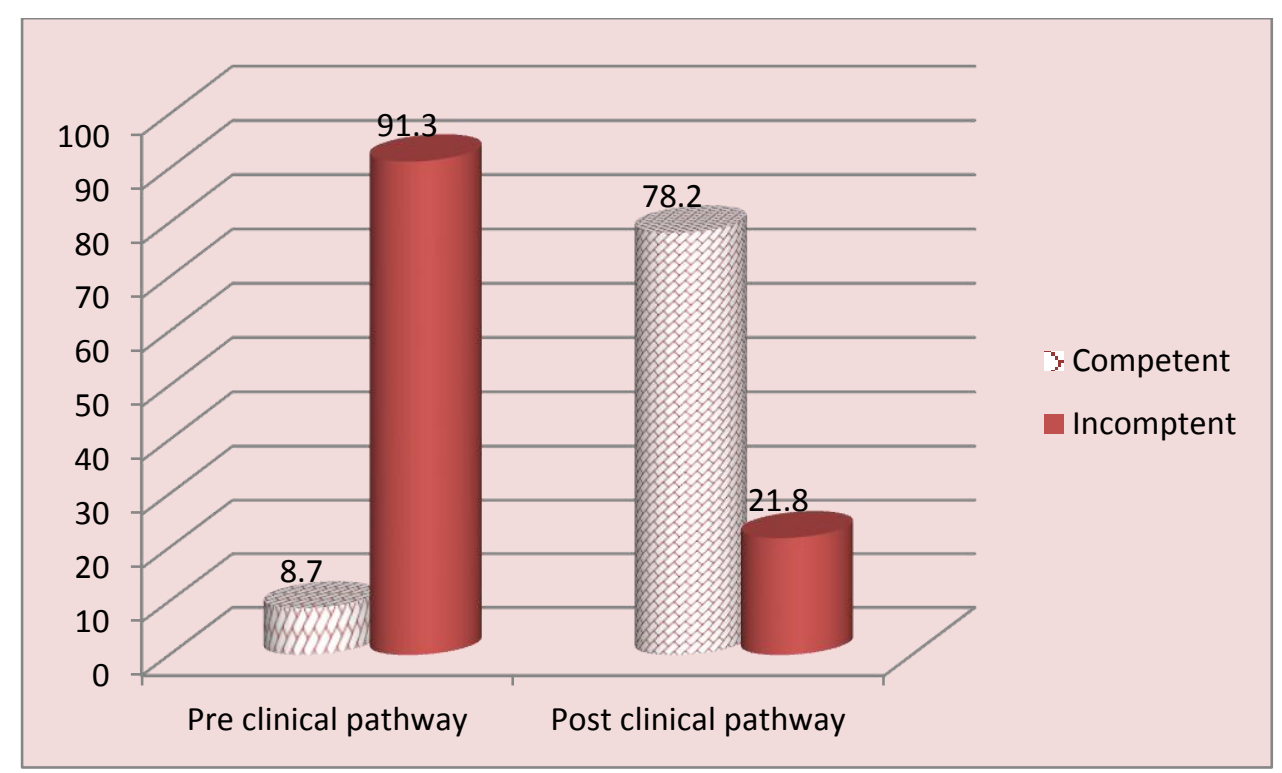

Figure (2): Percentage distribution of total practice scores of the studied nurses before and after clinical pathway implementation

Table (6): Percentage distribution of the studied neonates regarding effect of Clinical Pathway on their condition(No=150)

\begin{tabular}{|c|c|c|c|c|c|c|}
\hline \multicolumn{7}{|c|}{ Number of the Studied neonates $=(150)$} \\
\hline \multirow[t]{2}{*}{ Items } & \multicolumn{2}{|c|}{$\begin{array}{c}\text { Before } \\
\text { application of } \\
\text { the clinical } \\
\text { pathway }\end{array}$} & \multicolumn{2}{|c|}{$\begin{array}{l}\text { After application of } \\
\text { the clinical pathway }\end{array}$} & \multirow[b]{2}{*}{$\mathbf{X}^{2}$} & \multirow[b]{2}{*}{$P$ value } \\
\hline & No & $\%$ & No & $\%$ & & \\
\hline \multicolumn{5}{|l|}{ Feeding improvement } & \multirow{3}{*}{32.78} & \multirow{3}{*}{$<0.05^{*}$} \\
\hline Normal & 70 & 46.7 & 104 & 69.3 & & \\
\hline Hypoactive/ hyperactive & 80 & 53.3 & 46 & 30.7 & & \\
\hline \multicolumn{5}{|c|}{ Increased $\mathrm{O} 2$ requirement } & \multirow{3}{*}{$\begin{array}{c}109.7 \\
1\end{array}$} & \multirow{3}{*}{$<0.05^{*}$} \\
\hline Yes & 134 & 89.3 & 45 & 30.0 & & \\
\hline No & 16 & 10.7 & 105 & 70.0 & & \\
\hline \multicolumn{5}{|c|}{ Length of hospital stay in days } & \multirow{4}{*}{$\begin{array}{c}112.5 \\
2\end{array}$} & \multirow{4}{*}{$<0.05^{*}$} \\
\hline $10-$ & 10 & 6.7 & 81 & 54.0 & & \\
\hline $20-$ & 55 & 36.7 & 58 & 38.7 & & \\
\hline$\geq 30$ & 85 & 56.7 & 11 & 7.3 & & \\
\hline
\end{tabular}

*P Value $\leq 0.05$ Statistical significant differences $(\mathbf{S})$; $* * P$ value $\leq \mathbf{0 . 0 0 1}$ high Statistical significant differences (HS) 
Table (7): Percentage distribution of the studied nurses total knowledge and practice scores before and after clinical pathway implementation $(\mathbf{N o}=150)$

\begin{tabular}{|c|c|c|c|c|c|c|c|}
\hline \multirow{2}{*}{\multicolumn{2}{|c|}{ Items }} & \multicolumn{2}{|c|}{$\begin{array}{c}\text { Pre clinical } \\
\text { pathway } \\
(150) \\
\end{array}$} & \multicolumn{2}{|c|}{$\begin{array}{c}\text { Post clinical } \\
\text { pathway } \\
(150) \\
\end{array}$} & \multirow[t]{2}{*}{$\mathbf{X}^{2}$} & \multirow[t]{2}{*}{$\begin{array}{c}\mathbf{P} \\
\text { value }\end{array}$} \\
\hline & & No & $\%$ & No & $\%$ & & \\
\hline \multirow{3}{*}{ Knowledge } & - Poor & 104 & 69.3 & 5 & 3.3 & \multirow{3}{*}{186.48} & \multirow{3}{*}{$0.001^{* *}$} \\
\hline & - Average & 38 & 25.4 & 28 & 18.7 & & \\
\hline & - Good & 8 & 5.3 & 117 & 78.0 & & \\
\hline \multirow[t]{2}{*}{ Practice } & $\begin{array}{l}\text { Competent } \\
\text { done }\end{array}$ & 13 & 8.70 & 118 & 78.20 & \multirow[t]{2}{*}{89.83} & \multirow[t]{2}{*}{$0.000^{* *}$} \\
\hline & $\begin{array}{l}\text { Incompetent } \\
\text { done }\end{array}$ & 137 & 91.30 & 32 & 21.80 & & \\
\hline
\end{tabular}

$* P$ Value $\leq 0.05$ Statistical significant differences $(S)$

$* * P$ value $\leq 0.001$ high Statistical significant differences (HS)

Table (8): Relation between studied nurses' knowledge and practices and with their characteristics $(\mathrm{No}=150)$

\begin{tabular}{|c|c|c|c|c|c|c|c|}
\hline \multirow{2}{*}{$\begin{array}{l}\text { Personal } \\
\text { data }\end{array}$} & \multicolumn{2}{|c|}{ Knowledge } & \multicolumn{2}{|c|}{ ANOVA } & \multirow{2}{*}{$\begin{array}{l}\text { Practice } \\
x \pm S D\end{array}$} & \multicolumn{2}{|c|}{ ANOVA } \\
\hline & $\begin{array}{l}\text { N0: } \\
150\end{array}$ & $\mathrm{x} \pm \mathrm{SD}$ & $\begin{array}{l}\text { F/T } \\
\text { test }\end{array}$ & $\begin{array}{c}\mathbf{P} \\
\text { value }\end{array}$ & & $\begin{array}{l}\text { F/T } \\
\text { test }\end{array}$ & $P$ value \\
\hline & & & & & & \multicolumn{2}{|c|}{ Age in years } \\
\hline$-<20$ & 5 & $\begin{array}{l}28.00 \pm 1.0 \\
00\end{array}$ & \multirow{4}{*}{$\begin{array}{c}\text { F test } \\
3.24\end{array}$} & \multirow{4}{*}{$>0.05$} & $38.74 \pm 2.34$ & \multirow{4}{*}{$\begin{array}{l}\mathrm{F} \text { test } \\
0.852\end{array}$} & \multirow{4}{*}{$0.001^{*}$} \\
\hline$-20-<25$ & 75 & $\begin{array}{l}27.36 \pm 1.8 \\
42\end{array}$ & & & $40.81 \pm 3.28$ & & \\
\hline$-25-<30$ & 45 & $\begin{array}{l}26.53 \pm 3.3 \\
41\end{array}$ & & & $52.22 \pm 1.86$ & & \\
\hline$-\geq 30$ & 25 & $\begin{array}{l}25.64 \pm 3.3 \\
02\end{array}$ & & & $43.23 \pm 2.28$ & & \\
\hline \multicolumn{8}{|l|}{ Gender } \\
\hline Male & 13 & $\begin{array}{l}27.6 \pm 2.393 \\
90\end{array}$ & \multirow{2}{*}{$\begin{array}{c}\mathrm{T} \text { test } \\
1.18\end{array}$} & \multirow{2}{*}{0.058} & $49.55+4.28$ & \multirow{2}{*}{$\begin{array}{l}\mathrm{T} \text { test } \\
0.806\end{array}$} & \multirow{2}{*}{0.062} \\
\hline Female & 137 & $\begin{array}{l}26.74 \pm 2.70 \\
6\end{array}$ & & & $55.32+3.62$ & & \\
\hline
\end{tabular}




\begin{tabular}{|c|c|c|c|c|c|c|c|}
\hline \multicolumn{8}{|c|}{ Educational level } \\
\hline \begin{tabular}{|l|} 
Diploma of \\
secondary \\
nursing \\
school \\
\end{tabular} & 105 & & \multirow{3}{*}{$\begin{array}{l}\mathrm{F} \text { test } \\
4.02\end{array}$} & \multirow{3}{*}{0.00} & $36.14 \pm 4.32$ & \multirow{3}{*}{$\begin{array}{l}\mathrm{F} \text { test } \\
0.738\end{array}$} & \multirow{3}{*}{$0.001^{*}$} \\
\hline $\begin{array}{l}\text { Diploma of } \\
\text { Technical } \\
\text { institute of } \\
\text { nursing }\end{array}$ & 40 & & & & $48.61 \pm 3.88$ & & \\
\hline \begin{tabular}{|l|} 
Bachelor \\
degree in \\
nursing \\
science \\
\end{tabular} & 5 & & & & $53.62 \pm 2.82$ & & \\
\hline \multicolumn{8}{|c|}{ Years of experience } \\
\hline$<3$ & 58 & $\begin{array}{r}27.36 \pm 1.97 \\
0\end{array}$ & \multirow{3}{*}{$\begin{array}{l}\text { F test } \\
5.42\end{array}$} & \multirow{3}{*}{0.00} & $40.70 \pm 3.39$ & \multirow{3}{*}{$\begin{array}{l}\text { F test } \\
0.842\end{array}$} & \multirow{3}{*}{$0.001^{*}$} \\
\hline $3<6$ & 35 & $\begin{array}{l}27.65 \pm 1.69 \\
67\end{array}$ & & & $42.48 \pm 3.46$ & & \\
\hline $6<9$ & 28 & $\begin{array}{l}26.25 \pm 2.93 \\
9\end{array}$ & & & $53.12 \pm 2.88$ & & \\
\hline$\geq 9$ & 29 & $\begin{array}{l}25.41 \pm 3.85 \\
0\end{array}$ & & & $55.12 \pm 2.88$ & & \\
\hline
\end{tabular}

Table (9): Correlation between Total Knowledge and Total practice Pre and Post Clinical Pathway implementation (150)

\begin{tabular}{||l|c|c|c|c|}
\hline \multirow{2}{*}{ Items } & \multicolumn{2}{c|}{$\begin{array}{c}\text { Pre clinical } \\
\text { pathway (150) }\end{array}$} & \multicolumn{2}{c|}{$\begin{array}{c}\text { Post clinical } \\
\text { pathway(150) }\end{array}$} \\
\cline { 2 - 6 } & $\mathbf{R}$ & $\mathbf{p}$ & $\mathbf{r}$ & $\mathbf{p}$ \\
\hline Knowledge & 0.764 & $0.000^{* * *}$ & 0.668 & $0.000^{* *}$ \\
\hline Practice & 0.960 & $0.000^{* * *}$ & 0.790 & $0.000^{* *}$ \\
\hline
\end{tabular}

$* \mathbf{P}$ Value $\leq \mathbf{0 . 0 5}$ Statistical significant differences $(\mathrm{S})$;

${ }^{* *} \mathrm{P}$ value $\leq \mathbf{0 . 0 0 1}$ high Statistical significant differences (HS). 


\section{Tanta Scientific Nursing Journal}

\section{Discussion}

Respiratory distress is a common symptom affecting neonates. It is a condition of pulmonary insufficiency that in its natural course commences at or shortly after birth and increases in severity over the first 2 days of life. It usually affects premature neonates ${ }^{(\mathbf{1 0}) .}$

Clinical pathways have been developed in health care as multidisciplinary care plans that outline the sequence and timing of actions necessary for achievement of expected patient outcomes and organizational goals regarding quality, costs, patient satisfaction and efficiency. Additionally, the concept of clinical pathway refers to specific guidelines for care which describe patient treatment goals and define the sequence and timing of intervention for meeting those goals efficiently. So, the aim of this study was to evaluate the effect of clinical pathway on enhancing nursing care of neonates with respiratory distress syndrome ${ }^{(11) .}$

Regarding personal data of the studied nurses, the results of the present study revealed that, the mean age of the studied nurses was(25.46 \pm 5.262$)$. This may be attributed to the lack of nurses' knowledge .This result was similar to the results of study by El Baz, et al.,(2007)), who found in her study that age groups of nurses were between $20-<25$ year.
Concerning gender of the studied nurses, it was observed from the results of the current study that, the majority $(91.3 \%)$ of them were females. Moreover, the majority of them had diploma in nursing school. These results agreed with results found by Mohammed, (2007) ${ }^{(12)}$ who found that the majority of studied nurses were females, and had diplomas in nursing school.

Regarding to characteristics of the studied neonates with RDS, the present study found that, the mean gestational age was $33.65 \pm 6.98$ weeks and the mean weight of neonates on admission was $1980 \pm 298.68$. While, the current mean weight was $2370 \pm 150.89$. According to gender of the studied neonates. This might be due to respiratory distress syndrome affecting mainly preterm infants. This finding was supported by Mohamed (2010) ${ }^{(\mathbf{1 3})}$ who found that, more than half of neonates $(59.3 \%)$ were males. Also, stated that, In the modern era of neonatal management, male infants still have higher mortality and poorer long-term neurologic outcome ${ }^{(14)}$.

In relation to knowledge of the studied nurses, it is obvious from the current study that, the total knowledge scores post clinical pathway implementation about RDS had significant differences towards definition of RDS, leading causes, diagnosis, prevention and treatment compared with pre clinical pathway 
implementation knowledge scores. This result is supported by Amin,(2004) ${ }^{(15)}$ who reported a higher increase in study group subjects' knowledge mean scores immediately post nursing clinical pathway implementation than before, with a highly significant statistical differences. From the researchers' points of view this may due to lack of training courses related to neonatal nursing care.

Regarding to improvement of nurses' knowledge after intervention of clinical pathway on neonates with RDS. The results of the current study agreed with what reported by Refai, (2010) ${ }^{(16)}$ who found that in their study that there was a statistically significant difference between total mean scores of nurses' knowledge regarding meningitis pre and post $\mathrm{CP}$ guidelines implementation. The result of the current study matches with a study had done by Hussein, (2014) ${ }^{(17)}$ who found that there was a statistically significant difference regarding mean scores of nurses' knowledge about pneumonia between pretest and posttest scores.

The current study revealed that, there was a high statistical significant difference ( $P$ $<0,001)$ among nurses competent practices regarding nursing care of neonates with RDS before and after applying clinical pathway. This is in accordance with Mahmoud and Abd-El Sadik, ( 2013) ${ }^{(18)}$ who found that an obvious improvement in practice scores of the study group subjects immediately post nursing clinical pathway implementation than pre-nursing clinical pathway implementation. Additionally, Hussein, (2014) ${ }^{(17)}$ who found that clinical pathways embody practice guidelines, while at the same time allowing variations in the activity of the provider and in patient response.

Regarding the effect of clinical pathway on the studied neonates. The current study revealed that, there was an obvious improvement of neonates' condition. Whereas, increased 02 requirements of the majority of the studied neonates before application of clinical pathway compared with post test. Additionally, more than half of them had length of hospital stay less than 10 days after application of clinical pathway compared with the pre application of pathway. This may be due to the effect of newly techniques in application of care especially critically ill neonates. This was in accordance with Rhew et al., (2011) ${ }^{(19)}$ who found that, in their study that their findings in the $\mathrm{CP}$ group are including improving respiratory signs and/or symptoms and decreasing 02 daily requirements, increasing the ability to take oral medications and decreasing I.V. fluids faster than non- CP group and these were common criteria for early switch and early 
signs for neonates' discharge from hospital and reduce level of consciousness.In the same context Cheney, (2012) ${ }^{(20)}$ stated that, Clinical pathways are paths that health care professionals can follow which enable them to provide the best possible outcomes for the patients.

The results of the current study are supported by Patrick (2006) ${ }^{(21)}$ who found that in her study that there was a statistical significant difference between control group and pathway group regarding frequency of o /day from second till fifth day and the same picture was observed regarding to grand mean scores of frequency of $\mathrm{o}_{2} /$ day. Also Rhew et al., (2011) $^{(19)}$ who found in the study that there was a statistical significant difference between control group and pathway group regarding supplemental oxygen needs, as control group require more oxygen frequency than pathway group. From the researchers' point of view this may be due to competent practices of nurses regarding fluid management provision and frequency performance of suctioning procedures/day as prescribed for the neonates with RDS and regular follow up to neonates which lead to general improvement in outcomes of neonates' condition and early discharge from hospital.

\section{Conclusion}

\section{Based on the findings of this study, we} can conclude that:

Implementation of the nursing clinical pathway is highly effective method to improve nurses' knowledge and can enhancing nursing care of neonates with respiratory distress by raising nurses' knowledge, enhancing their practice regarding $\mathrm{O}^{2}$ requirement, improved neonatal outcomes and reduces their length of hospital stay.

\section{Recommendations:}

\section{Based on the results of the current}

\section{study, the following recommendations}

\section{were reached:}

- Clinical pathway on nursing care of neonates with respiratory distress should be applied for neonates with respiratory distress in different settings

- Provision of regular training programs for nurses about $\mathrm{CP}$ of care of neonates with RDS on a wider scale in similar settings to further confirm its utility and benefits in improving nurses' knowledge and practice.

- The clinical pathway approach of care can be generalized for utilization by health team members in different pediatric healthcare settings. 


\section{References:}

1- Martin, RJ., and Fanaroff, AA. The Preterm Lung and Airway: Past,Present, and Future. pregnancy (twins or more) Pediatr Neonatol2013; 18(13): 36-43.

2-McCance, K., and Huether, S. Prenatal development of the alveolar unit. (Pathophysiology: the biological basis for disease in adults and children, $6^{\text {th }}$ ed 2010;1122-1128. St Louis, Mosby.

3- American Lung Association. Incidence and prevalence of respiratory distress syndrome worldwide.

Retrieved Wikipedia, the free encyclopedia. Article Review.2015-03-09.

4- Hamvas, A., Cole, F., and Nogee, ,LM. Genetic disorders of surfactant proteins. Neonatology2007;91(1): 311317.

5- Negi, R.. Pande, D., Kumar, A., Khanna, R.S., and Khanna, H.D. Newborn Respiratory Distress: Airway Abnormalities J. Trop. Pediatr., 2012;58(11):326-328.

6- Steinhorn, RH., Kinsella, JP., and

Pierce, C. Intravenous sildenafil in the treatment of neonates with persistent pulmonary hypertension, $\mathrm{J}$ Pediatric. 2009; 155(6): 841-847.

7- Wambach JA, and Hamvas A. Respiratory Distress Syndrome in The Neonate. In Fanaroff and Martin's
Neonatal-Perinatal Medicine. $10^{\text {th }}$ ed Philadelphia, PA: Elsevier Saunders Co.2015:365-368.

8- Zaichkin ,J. Newborn Intensive Care: What Every Parent Needs to Know, $3^{\text {rd }}$ ed, Elk Grove Village, Ill, American Academy of Pediatrics 2009;:14521456.

9- The Right Diagnosis . Statistics by Country for Premature Birth. Avalible at http://www.Right Diagnosis .com.2016

10- Martin, R. Prevention and treatment of respiratory distress syndrome in preterm infants pediatr .j.2015;12(6):133-139.

11- Rhew, D.C., Tu, J., Offman, G.S., and Henning, J.M. Richards, MS.; Weingarten, Scott R. Early Switch and Early Discharge Strategies in Patients With Community-Acquired Pneumonia A Meta-analysis. Arch Intern Med2011; 161(5): 722-727.

12- Mohammed, S. M. Quality of Nurses' Performance In Neonatal Intensive Care Units, Master Thesis, Faculty of Nursing, Benha University, Egypt.2007; 15-20.

13- Mohamed, S. Quality of Nursing Care for Neonates with Respiratory Distress Syndrome outcomes master thesis, Faculty of Nursing, Benha University.2010 
14- Alison L. Kent, Ian M. R. Wright, Mohamed E. Abdel-Latif. Mortality and Adverse Neurologic Outcomes Are Greater in Preterm Male Infants. The New South Wales and Australian Capital Territory Neonatal Intensive Care Units Audit Group. Pediatrics Jan 2012, 129 (1) D1-D12.

15- Amin, F.M. Intervention Nursing Program for Care of High Risk Neonate at Mansoura Hospitals, Doctorate thesis, Faculty of Nursing, Ain Shams University, Egypt. 2004

16- Refai, A.S. Impact of a designed nursing clinical pathway guidelines on acute myocardial infarction patients' outcomes doctorate thesis, Faculty of Nursing, Benha University. Egypt 2010.

17- Hussein, H.A. Effect of Using Clinical Pathway on Improving Clinical Outcomes of Infants with Pneumonia World J. Med. Sci 2014;. 11 (1): 120-131.

18- Mahmoud, F.S. and Abd-EISadik B.R. Effect of clinical pathway regarding promoting quality nursing care of children with meningitis exposed to invasive procedures. Journal of American Science, 2013; 9(8)383-393.
19-Rhew，D.C., Tu，J., Offman, G.S., and Henning, J.M. Richards, MS.; Weingarten, Scott R. Early Switch and Early Discharge Strategies in Patients With Community-Acquired Pneumonia A Meta-analysis. Arch Intern Med2011; 161(5): 722-727.

20- Cheney, J.L. : Evaluation of effectiveness of a clinical pathways for bronchiolitis. A thesis submitted for awarding master of applied science(research). Centre of Nursing Research, School of Nursing, Queensland University of Technology2012.

21-Patrick, T.O. Critical pathways in cardiovascular medicine, $2^{\text {nd }}$ ed. Lippincott Williams \& Wilkins, 2006;:336-339. 